\title{
Albumin and Serum Vitamin A Status of Malnourished Children
}

\author{
Egbe Edmund Richard, Eworo Raymond Ekong* \\ Department of Medical Laboratory Science, University of Calabar, Calabar, Nigeria \\ Email address: \\ raymondeworo@yahoo.com (E. R. Ekong) \\ ${ }^{*}$ Corresponding author
}

To cite this article:

Egbe Edmund Richard, Eworo Raymond Ekong. Albumin and Serum Vitamin a Status of Malnourished Children. European Journal of Clinical and Biomedical Sciences. Vol. 4, No. 1, 2018, pp. 6-11. doi: 10.11648/j.ejcbs.20180401.12

Received: November 26, 2017; Accepted: December 14, 2017; Published: March 23, 2018

\begin{abstract}
Malnutrition remains a major health problem in the third world countries, and is a key factor to the high death rate among children below five years old. This study aimed to determine serum vitamin A, mid-upper arm circumference (MUAC), and albumin levels of malnourished children and their well-fed counterparts. A total of one hundred (100) children comprising of fifty (50) malnourished children under the age of five years and fifty (50) well-fed age-matched children were recruited into this study. Mid upper arm circumference (MUAC) measurement was used to categorize the children into malnourished and the well-fed groups. The malnourished were further classified into kwashiorkor and marasmic cohorts. Serum vitamin A and albumin levels were determined by colorimetric methods. Data were analyzed using SPSS version 20.0 statistical package, differences between and variations among groups were determined by Student's t-test and ANOVA respectively while the association between variables by Pearson's correlation. Differences were considered statistically significant at $p \leq 0.05$. Serum vitamin A, MUAC and albumin levels of the well-fed group were significantly higher $(\mathrm{p}<0.05)$ than those of the malnourished. Comparing the well-fed, the kwashiorkor and the marasmic groups, the mean serum vitamin A, MUAC and albumin of the well-fed were significantly higher $(p=0.001)$ than those of the kwashiorkor and marasmic groups. Mean albumin level of the kwashiorkor was significantly lower $(\mathrm{p}<0.05)$ than that of marasmic group. Mean MUAC of the kwashiorkor subjects was significantly higher $(\mathrm{p}<0.05)$ than that of the marasmic subjects. Serum vitamin A was not significantly different $(\mathrm{p}=0.724)$ between the kwashiorkor and the marasmic groups. In the marasmic subjects mean serum vitamin A correlates negatively with albumin $(\mathrm{r}=-0.517, \mathrm{p}=0.011)$. In the kwashiorkor subjects, serum vitamin A correlates negatively with albumin $(\mathrm{r}=-0.080$, $\mathrm{p}=0.690)$. In the well-fed children, serum vitamin A correlates positively with albumin $(\mathrm{r}=0.340, \mathrm{p}=0.016)$. Conclusion: malnourished children with kwashiorkor and marasmus have lower albumin, serum vitamin A and MUAC compared with the well-fed children.
\end{abstract}

Keywords: Albumin, Vitamin A, MUAC, Malnutrition, Children

\section{Introduction}

The first insertion of the millennium development Goals (MDGS) is the "eradication of extreme poverty and hunger" [1]. Economic deprivation and poverty affect children more; resulting in childhood malnutrition. Malnutrition is a state of inadequate or improper nutrition, which may be as a result of a combination of insufficient intake of proteins, calories, vitamins and minerals as well as frequently untreated or poorly treated infections in children of developing countries $[2,3,4]$. An adequate diet should provide, energy in the form of carbohydrates, fats and proteins, essential as well as nonessential amino acids and fatty acids which serve as building blocks for the synthesis of structural and functional proteins and lipids, vitamins and minerals, which function as coenzymes in vital metabolic pathways. One or all of these could be missing in the diet resulting in primary malnutrition (dietary in origin) or the nutrient supply is adequate but malnutrition may result from nutrient malabsorption, impaired nutrient use or storage, excess nutrient loss, or increased need for the nutrients. Vitamin A deficiency is a common occurrence in malnourished children. Vitamin A deficiency (VAD) refers to serum retinol $\leq 20 \mu \mathrm{g} / \mathrm{dL}$ or $\leq 0.7$ 
$\mu \mathrm{mol} / \mathrm{L}$ or vitamin $\mathrm{A}<60.0 \mathrm{iu} / \mathrm{dL}$, subclinical VAD can substantially increase the risk for childhood mortality from infectious and non-infectious diseases [5, 6].

Many studies have linked vitamin A deficiency to the risk of being stunted and weight lost in malnourished children [7, 8]. Vitamins are organic substances in food which are required in small amounts but cannot be synthesize by the body in adequate quantities [9]. Thirteen vitamins are necessary for health; four are fat soluble the remainder being water soluble.

Globally, vitamin A deficiency (VAD) affects 140 million children, 4.4 million of whom have xerophthalmia [10, 11]. More than 9 million children and 6 million mothers are Vitamin A deficient in Nigeria $[12,13]$. It has been reported that $29.5 \%$ of children under-five are suffering from Vitamin A Deficiency $[14,15,16]$. Vitamin A Deficiency (VAD) contributes up to 25 per cent of infant, child and maternal mortality in Nigeria due to reduced resistance to protein energy malnutrition, acute respiratory infection, measles, malaria and diarrhea [17]. Vitamin A deficiency may exist as a component of a broad spectrum of nutritional disorders referred to as Protein Energy Malnutrition (PEM) [18], a continuum of nutritional disorders with kwashiorkor and marasmus at both extremes, with other forms in between them, depending on the proportion of protein to calorie deprivation.

PEM is a range of clinical syndromes characterized by an inadequate dietary intake of protein and calories to meet the body's need for growth, maintenance, and specific function. It is generally a nutritional problem that results from varying proportions of protein and calorie deficiency in infants and young children of developing countries [19]. The major risk factors that can predispose a child to having PEM include poverty, lack of access to quality food, cultural and religious food customs, poor maternal education, inadequate breast feeding, and lack of quality healthcare [20]. A quick and simple way to determine whether or not a child is malnourished is by measurement of mid-upper arm circumference (MUAC) [21].

There is a universal coercion to tackle the question of malnutrition particularly in children. Micronutrient supplementation and immunization programs to curb childhood malnutrition and infections are on-going; however, multifarious interactions between untreated malnutrition and vitamin deficiencies may thwart the outcome of the programs $[22,24]$. Malnutrition is a consequence of extreme poverty among people with scarcely any substantial means of livelihood. Studies on nutritional status of children are scarce, this work therefore aimed at assessing serum vitamin A, albumin and mid-upper arm circumference of malnourished and well-fed children.

\section{Materials and Methods}

This study was conducted in Calabar, Cross River State. Ethical clearance was obtained from the Research Ethical Committee of the Cross River State Ministry of Health; informed consents were also obtained from the parents of each child. A standard venepuncture method was used to obtain five milliliters $(5 \mathrm{ml})$ of blood from all the subjects. The blood was dispensed into plain containers and allowed to clot, then centrifuged at 3000rpm for 5 minutes and the serum stored frozen until analyses. Serum vitamin A was estimated using Trichloroacetic acid (TCA) method of NeeldPearson [23], following extraction with petroleum ether. Serum albumin was estimated based on Bromocresol Green Method of Doumas et al., [25], using a kit obtained from Quimica Clinica Apliciada S. A. (QCA, S. A.). Mid upper arm circumference was measured using a MUAC tape around the left arm, which is relaxed and hanging down the side of the body, with the tape neither pinching the arm nor left loose. Statistical analysis: The data generated were analyzed using SPSS version 20.0 statistical package, differences between groups were determined using Student's t-test, variations among groups by ANOVA and relationship between parameters using Pearson's correlation, differences were considered statistically significant at $\mathrm{P}<0.05$.

\section{Results}

Mean serum vitamin A, MUAC and albumin of the wellfed subjects $\quad(125.04 \pm 6.02 \mathrm{iu} / \mathrm{dl}, \quad 15.73 \pm 0.18 \mathrm{~cm}$, $4.06 \pm 0.08 \mathrm{~g} / \mathrm{dl})$ were significantly higher $(\mathrm{P}<0.05)$ than those of the malnourished children, $(25.74 \pm 2.01 \mathrm{iu} / \mathrm{dL}$, $9.73 \pm 0.25 \mathrm{~cm}$ and $2.45 \pm 0.08 \mathrm{~g} / \mathrm{dL}$ ) respectively, table 1 . Mean serum vitamin A, MUAC and albumin of the well-fed $(125.04 \pm 6.02 \mathrm{iu} / \mathrm{dL}, 15.73 \pm 0.18 \mathrm{~cm}$ and $4.06 \pm 0.08 \mathrm{~g} / \mathrm{dL})$ were significantly higher $(\mathrm{p}=0.001)$ than those of the kwashiorkor $(22.56 \pm 2.56 \mathrm{iu} / \mathrm{dL}, 11.37 \pm 0.13 \mathrm{~cm}$ and $2.02 \pm 0.04 \mathrm{~g} / \mathrm{dL})$ and marasmic $(29.48 \pm 3.06 \mathrm{iu} / \mathrm{dL}, 8.55 \pm 0.2 \mathrm{~cm}$ and $2.95 \pm 0.06$ $\mathrm{g} / \mathrm{dL})$ groups respectively. Mean albumin levels of the kwashiorkor $(2.02 \pm 0.04 \mathrm{~g} / \mathrm{dL})$ was significantly lower $(\mathrm{p}=0.001)$ than the value for marasmic group $(4.06 \pm 0.08 \mathrm{~g} / \mathrm{dL})$. Mean MUAC of the kwashiorkor subjects $(11.37 \pm 0.13 \mathrm{~cm})$ was significantly higher $(\mathrm{p}<0.05)$ than that of the marasmic subjects $(8.55 \pm 0.25 \mathrm{~cm})$. Serum vitamin A was not significantly different $(p=0.724)$ between the kwashiorkor and marasmic groups, table 2.

Comparison of serum Vitamin A, MUA and albumin in marasmic, kwashiorkor and well-fed subjects using Turkey HSD post hoc analysis. The mean difference in serum vitamin A between the well-fed and the kwashiorkor (102.48 $\mathrm{iu} / \mathrm{dL}$ ) was higher than that between the well-fed and the marasmic children $(95.56 \mathrm{iu} / \mathrm{dL})$. The mean difference in MUAC between the well-fed and kwashiorkor subjects $(4.37 \mathrm{~cm})$ was lower than that between the well-fed children and marasmic children $(7.18 \mathrm{~cm})$. The mean difference in albumin levels between the well-fed children and the kwashiorkor children $(2.04 \mathrm{~g} / \mathrm{dL})$ was higher than that between the former and the marasmic children $(1.11 \mathrm{~g} / \mathrm{dL})$, Table 3. In the marasmic subjects mean serum vitamin A correlates negatively with albumin $(\mathrm{r}=-0.517, \mathrm{p}=0.011)$ figure 1. In the well-fed children, vitamin A correlates positively with albumin $(\mathrm{r}=0.340, \mathrm{p}=0.016)$, figure 3 . In the kwashiorkor children, serum vitamin A correlates negatively with albumin levels $(r=0.080, p=0.690)$ figure 2 . 
Table 1. Serum vitamin A, MUAC and Albumin levels of malnourished and the well-fed children.

\begin{tabular}{lllll}
\hline Parameters & Malnourished $(\mathbf{n}=\mathbf{5 0})$ & Well-fed $(\mathbf{n}=\mathbf{5 0})$ & Cal. t & P-value \\
\hline Vitamin A (iu/dL) & $25.74 \pm 2.01$ & $125.04 \pm 6.02$ & 15.65 & 0.001 \\
MUAC (cm) & $9.73 \pm 0.25$ & $15.73 \pm 0.18$ & 19.49 & 0.001 \\
Albumin $(\mathrm{g} / \mathrm{dL})$ & $2.45 \pm 0.08$ & $4.06 \pm 0.08$ & 14.50 & 0.001 \\
\hline
\end{tabular}

Table 2. Serum vitamin A, MUAC and Albumin levels of the well-fed, marasmic and kwashiorkor subjects.

\begin{tabular}{llllll}
\hline Parameters & Well-fed $(\mathbf{n}=\mathbf{5 0})$ & Kwashiorkor $(\mathbf{n}=\mathbf{2 7})$ & Marasmic $(\mathbf{n}=\mathbf{2 3})$ & Cal. $\mathbf{F}$ & p-value \\
\hline Vitamin A (iu/dL) & $125.04 \pm 6.02$ & $22.56 \pm 2.56$ & $29.48 \pm 3.06$ & 122.29 & 0.001 \\
MUAC (cm) & $15.73 \pm 0.18$ & $11.37 \pm 0.13$ & $8.55 \pm 0.25$ & 348.1 & 0.001 \\
Albumin (g/dL) & $4.06 \pm 0.08$ & $2.02 \pm 0.04$ & $2.95 \pm 0.06$ & 187.01 & 0.001 \\
\hline
\end{tabular}

Table 3. Serum Vitamin A, MUA and albumin in marasmic, kwashiorkor and control subjects using Turkey HDS post hoc analysis.

\begin{tabular}{|c|c|c|c|c|}
\hline Groups & Well-fed $(n=50)$ & Kwashiorkor $(n=27)$ & Mean diff. & P-value \\
\hline Vit A (iu/dL) & $125.04 \pm 6.02$ & $22.56 \pm 2.56$ & 102.48 & 0.001 \\
\hline MUAC (cm) & $15.73 \pm 0.18$ & $11.37 \pm 0.13$ & 4.37 & 0.001 \\
\hline \multirow[t]{2}{*}{$(\mathrm{g} / \mathrm{dL})$} & $4.06 \pm 0.08$ & $2.02 \pm 0.04$ & 2.04 & 0.001 \\
\hline & Well-fed $(n=50)$ & Marasmic $(n=23)$ & & \\
\hline Vit A (iu/dL) & $125.04 \pm 6.02$ & $29.48 \pm 3.06$ & 95.56 & 0.001 \\
\hline \multirow[t]{2}{*}{$\mathrm{Alb}(\mathrm{g} / \mathrm{dL})$} & $4.06 \pm 0.08$ & $2.95 \pm 0.06$ & 1.11 & 0.001 \\
\hline & Kwashiorkor $(n=27)$ & Marasmic $(n=23)$ & & \\
\hline Vit A (iu/dL) & $22.56 \pm 2.56$ & $29.48 \pm 3.06$ & -6.92 & 0.724 \\
\hline MUAC (cm) & $11.37 \pm 0.13$ & $8.55 \pm 0.25$ & 2.82 & 0.001 \\
\hline $\mathrm{Alb}(\mathrm{g} / \mathrm{dL})$ & $2.02 \pm 0.04$ & $2.95 \pm 0.06$ & -0.93 & 0.001 \\
\hline
\end{tabular}

$\mathrm{KEY}$ : diff=difference, $\mathrm{Alb} .=$ albumin, vit. $\mathrm{A}=$ vitamin $\mathrm{A}, \mathrm{MUAC}=$ mid-upper arm circumference.

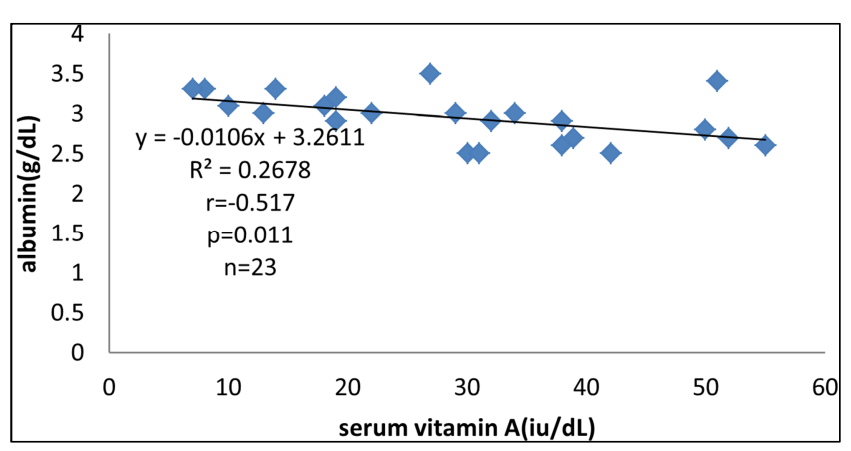

Figure 1. Correlation of serum vitamin A against albumin in marasmic children.

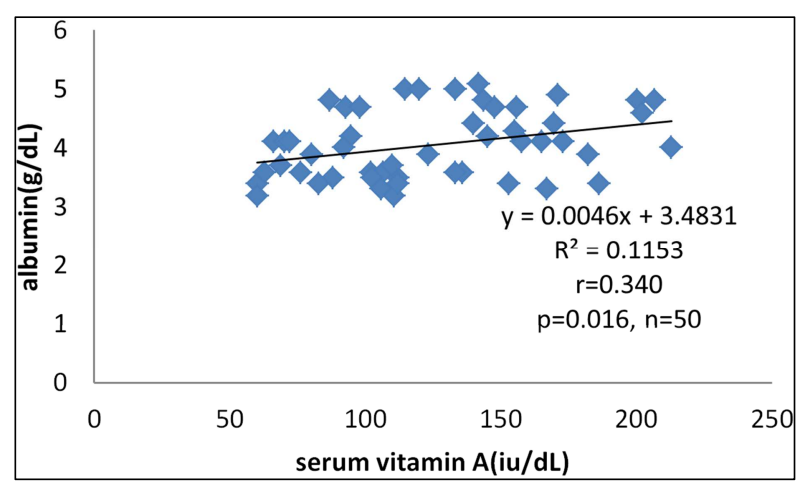

Figure 2. Correlation of serum vitamin A against albumin in the well-fed children.

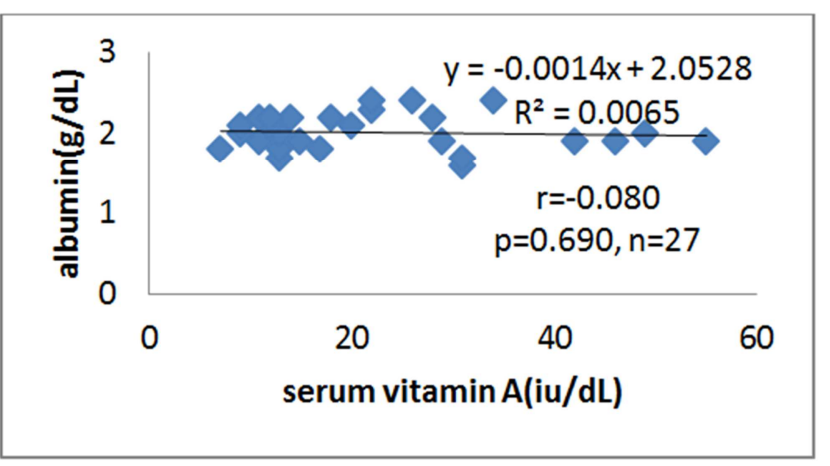

Figure 3.Correlation of serum vitamin A against albumin in the kwashiorkor children.

\section{Discussion}

Protein energy malnutrition manifest in a continuum of diseases with kwashiorkor and marasmus occurring at both ends of the specimen with other overlapping forms defined in-between; based on varying proportions of calorie and protein deficiency in children. This study shows that serum vitamin A, mid upper arm circumference (MUAC) and albumin values vary with nutritional status of growing children and in malnourished children, the parameters are significantly lower than those of the well-fed counterpart. The significantly lower levels of vitamin A, MUAC and albumin in the malnourished children may be due to low 
intake and malabsorption of vitamin A-rich foods, diminished bioavailability of provitamin A, exhaustion of hepatic stores of vitamin A, reduced hepatic albumin synthesis and reduced retinol binding protein required for vitamin A transport from the liver, increased demand for vitamin A and suppression of anabolic processes in order to compensate for increased energy requirement of the body in the malnourished, muscle wasting and depletion of proteins of the gut compartment resulting from imbalances between nutrient intakes and body requirement. The findings are similar to those reported in a number of studies [26, 27, 28, 29], where significantly lower values of Vitamin A, MUAC or BMI in the malnourished compared with the well-fed cohort were demonstrated.

When the kwashiorkor, marasmic and well-fed subjects were compared, the significantly lower mean serum vitamin A of the marasmic and the kwashiorkor, suggest that deficiency of vitamin A may be an intrinsic component of all forms of malnutrition. However, kwashiorkor children have worst cases of vitamin A and albumin deficiency compared with the marasmic while muscle wasting depicted by MUAC values are most horrible in marasmic children than the kwashiorkor. Also, Serum vitamin A was higher in the marasmic group than the kwashiorkor, this may suggest that vitamin A metabolism may be protein dependent, and the visceral proteins are relatively safer in marasmic subjects thereby indirectly sparing vitamin A. These observations are similar to those of Nathalie et al., [30], who reported lower levels of serum vitamin A in kwashiorkor subjects than in the marasmic group. The lower level of vitamin $A$ in the kwashiorkor group may be due to deficiency of binding or transport proteins in these subjects. Muscles wasting in the marasmic subjects results in significant reduction in MUAC as the proteins of the somatic compartments and subcutaneous fats are catabolized as an attuned response that serves provide the body with amino acids as alternative source of energy during calorie deprivation with the resultant atrophy of muscle mass reflected by reduced mid upper arm circumference (MUAC) values. Albumin on the other hand is significantly lower in the kwashiorkor than in the marasmic children which may be due to relative protein deficiency in the former, a similar finding was reported by studies of Reeds \& Laditan; Malcolm [31, 32]. Protein deficiency results in low albumin and marginal weight loss, the true weight loss often masked by fluid retention, [33, 34, 35]. Mid upper arm circumference and albumin differ significantly between the well- fed, marasmic and the kwashiorkor groups. This may be due to differences in nutritional status of the well-fed children and diverse nutritional requirements of the undernourished with consequent altered metabolic processes that serve to improve the lost protein-energy-balance. Thus, subclinical deficiency of micronutrients may predispose a child to frequent and severe common infections hence eliciting a vicious cycle of subnormal nutrition and intermittent infections that culminate in one of the well characterized forms of malnutrition such as kwashiorkor and marasmus. Micronutrient deficiency and the predisposition of affected children to recurrent infection have been demonstrated by Black, [36, 37, 38].

Protein energy malnutrition may begin as mild forms of under-nutrition with deficiency of vitamin $A$ as the overriding feature, which initiates series of events exemplified by impaired nutrient absorption, impaired hepatic protein synthesis, muscle wasting and depletion of proteins of the visceral compartment that translate into kwashiorkor, marasmus and marasmic kwashiorkor, depending on the ratio of protein to calorie deficiency. An interdependent relationship exist between protein and vitamin A status, as serum levels of vitamin A may be lowered by exhaustion of tissue reserves or following protein deficiency and impairment of mobilization of liver stores as the hepatic retinol-binding protein synthesis is impaired in proteincalorie malnutrition.

The negative correlation between albumin and MUAC in the marasmic subjects may be as a result of muscle wasting and consequent reduction of the proteins of the somatic body compartment with relative sparing of the proteins of the visceral body compartment (albumin) in these subjects. Vitamin A correlated positively with MUAC in the marasmic subject suggesting that deficiency of vitamin A and reduction in MUAC or improvement in vitamin $\mathrm{A}$ and increase in MUAC may progress together, thus; as nutritional status improves, vitamin $\mathrm{A}$, and MUAC values improve as well at all points on the nutrition scale. This is in line with the findings of Donnen et al., [39], who reported improvement in anthropometrics, albumin and vitamin A following replacement of vitamin A in children. A significant negative correlation between serum vitamin A and albumin observed in the marasmic group may be due to the fact that as malnutrition progresses with deficiency of vitamin A in these subjects the proteins of the visceral body compartment (albumin) are gradually spared. The finding is in accordance with that of Vinicius et al., [40], who reported that growth retardation and loss of muscle occurring in marasmic children may be due to an evolving adaptive response to calorie and energy deficits with consequent diversion of energy from muscle and subcutaneous tissues to more metabolically active organs. Calorie deficiency can lead to abnormal lipid metabolism with marked reduction of adipose tissue mobilized for fuel [41]. Thus, malnutrition may be easily diagnosed by anthropometric measurements and physical examination for signs of vitamin A deficiency as these may allow evaluation of individual dietetic states. Linear growth retardation, wasting, underweight and edema each may correspond to a diverse history of nutritional shortfalls.

In the well-fed serum vitamin $\mathrm{A}$ and albumin levels correlates significantly positive, suggesting that as albumin increases, serum vitamin A accumulates in well-fed children. However, in the marasmic and kwashiorkor children, serum vitamin A and albumin levels correlates negatively. More so, the strength of the associations and the slope of the graphs are not the same, suggesting that the corresponding rate of diminution of serum vitamin $\mathrm{A}$ and albumin in marasmic and 
kwashiorkor children are not the same. The relative rate of loss of serum vitamin A over albumin level suggests that more albumin changes occur per change in vitamin $\mathrm{A}$ in the kwashiorkor compared with the marasmic children, where the rate of change in serum vitamin $\mathrm{A}$ and albumin is near proportionality.

Thus, the relative sparing of visceral protein stores (albumin) in the marasmic children compared with kwashiorkor children, also preserves vitamin A. Vitamin A deficiency associated growth retardation in the marasmic children may occur in extreme cases of vitamin A deficits where there may equally be further losses of visceral protein backup. In the well-fed children serum vitamin A correlates positively with MUAC and albumin this may suggest that vitamin A stores support all aspects of growth and development in children and that vitamin A dearth is central to all forms of malnutrition in children.

\section{Conclusion}

The study concludes that serum vitamin A, Albumin and MUAC draw a parallel with the nutritional status of children and malnourished children have lower albumin, Vitamin A and MUAC values compared with the well-fed children. Also, vitamin A deficiency is central to all forms of malnutrition in children as vitamin A stores support all aspects of growth and development in children. Vitamin A losses occur more in Kwashiorkor than in marasmic children.

\section{References}

[1] Millennium Development Goals, "Current progress in Nigeria", United Nations Development Programme-Nigeria; 2012.

[2] Wilson E. D. and Fisher K. H, "Principles of nutrition $3^{\text {rd }}$ ed. John Wiley and son incorporate", Oxford, 1994; 216-224.

[3] Allen, L. H., Rosado, J. L., Casteline, J. E, "Lack of haemoglobin response to iron supplementation in anemic Mexican preschoolers with multiple micronutrient deficiencies", American Journal of Clinical Nutrition, 2000; 17: 1485-1494.

[4] World Health Organization. "World health report, Geneva", (2002).

[5] Rice A. L, Sacco L, Hyder A, Black R. E, "Manutrition as an underlying cause of childhood deaths associated with infectious diseases in developing countries," Bulletin of World Health Organization, 2007; 78: 1207-21.

[6] Kara A. Bresnahan and Sherry A. Tanumihardjo, "Undernutrition, the acute phase response to infection and its effects on micronutrient status indicators", Advances in Nutrition, 2014; vol. 5: 702-711, doi:10.3945/an.114.006361.

[7] Fuchs G. J, Ausayakhun S, Ruckphaopunt S, Tansuhaj A, Suskind R. M, "Relationship between vitamin A deficiency, malnutrition, and conjunctival impression cytology", American Journal of Clinical Nutrition, 1994; 60: 293-8.
[8] Requejo JH, Bryce J, Barros AJ, Berman P, Bhutta Z, Chopra M, Daelmans B, de Francisco A, Lawn J, Maliqi B, Mason E, Newby H, Presern C, Starrs A, Victora CG, "Countdown to 2015 and beyond: fulfilling the health agenda for women and children", Lancet, 2015; 385 (9966): 466-76.

[9] Barber, E. W., Roles, OA, "Vitamin A status of children in Srilanka," American Journal of clinical nutrition", 2000; 32: 84-91.

[10] Black, R. E., Allen, L. H., Bhutta, Z. A., Caulfield, L. E., De Onis, M., Ezzati, M., Mathers, C., Rivera, J, "Maternal and child undernutrition: global and regional exposures and health consequences", Lancet, 2008; 371: 243-260.

[11] West, K. P. Jr, "Extent of vitamin A deficiency among preschool children and women of reproductive age", Journal of Nutrition, 2002; 132 (9 Suppl): 2857S-2866S.

[12] United Nations international Children's Education Fund (UNICEF). "Strategizing Micronutrient deficiency control in Nigeria-from Policy to Workplan" Lagos: UNICEF.

[13] Ajenifuja B, "Paediatrics Health Care in Nigeria: Yesterday, Today and Tomorrow" Nigerian Journal of Paediatrics, 2011; 38 (4): $146-158$.

[14] Duffy, E. \& Gibney, MJ, "Use of a food-consumption database with packaging information to estimate exposure to foodpackaging migrants: expoxidized soybean oil and styrene monomer. Food Additives Contamination”, 2007; 24 (2): 216-25.

[15] Ojofeitimi, EO, "Malnutrition and approaches to improving the nutritional status of children in low income settings. $h \mathrm{ttp}: / /$ www.oauife.edu.ng/wp-content/uploads/2013/05/.

[16] Prentice AM, Nabwera H, Unger S, Moore SE, "Growth monitoring and the prognosis of mortality in low-income settings" American Journal of Clinical Nutrition, 2016; 03: 681-682.

[17] Policy Project of Nigeria "Reproductive Health in Nigeria, Situation, Response, and Prospects" Key Issues Abuja policy Project, 2002.

[18] Müller, O., \& Krawinkel, M., "Malnutrition and health in developing countries", CMAJ: Canadian Medical Association Journal, 2005; 173 (3), 279-286.

[19] Nemer L, Gelband H, Jha P., "Commission on Macroeconomics and Health. The evidence base for interventions to reduce malnutrition in children under five and school-age children in low- and middle-income countries", CMH working papers no WG5: 11. 2001, Geneva: World Health Organization.

[20] Nnakwe, N., "The effect and causes of protein-energy malnutrition in Nigerian children", Nutrition Research, 1995; 15: 785-794.

[21] Myatt M., Khan, T., Collins, S., "A review of methods to detect severe malnutrition in the community for their admission into community based therapeutic feeding centers", Food and Nutrition Bulletin, N0 3 supplement, the United Nation University, 2006; 1142-1144.

[22] World Health Organization "Nutrition: challenges", (2009; http://www.who.int/nutrition/challenges/en/index.html.

[23] Neeld, JB, Pearson, WN, "Macro and micro methods for the determination of serum vitamin A using TCA", Journal of Nutrition, 1963; 79: 454-462. 
[24] Young, H., Borrel, A., Holland, D., Salama, P, "Public nutrition in complex emergencies" Lancet, 2004; 365: 18991909.

[25] Doumas, B. T., Watson, W. A., Biggs, HG, “Albumin standard and measurement of serum albumin with Bromocresol green" Clinica Chimica Acta, 1971; 31: 87-96.

[26] Reddy, V., Mohanram, M., Raghuramulu, N, "Serum retinolbinding protein and vitamin A levels in malnourished children", Acta of paediatric scandal, 1979; 68 (1): 65-69.

[27] Ikekpeazu E. J., Neboh, E. E., Maduka I. C., Ezedigbo, A. N \& Odetunde, T, "Serum vitamin A levels in children with protein energy malnutrition", Current Pediatric Research, 2010; 14 (1): 9-13.

[28] Moriese, G. Raz, A., Mancini, G., Carbonara, A. O, "Regulation of retinol binding protein metabolism by vitamin A status in the human", Journal of Biological Chemistry, 1997; 247: 2442-2450.

[29] Ugwuja, E. I., Nwosu, K. O., Ugwu1, N. C. and Okonji, M, "Serum Zinc and Copper Levels in Malnourished Pre-School Age Children in Jos, North Central Nigeria", Pakistan Journal of Nutrition, 2007; 6 (4): 349-354.

[30] Nathalie Pascal, Emile Kou Santa Amouzou, Ambeliou Sanni, Fares Namour, Idrissia Abdelmouttaleb, Michel Vidailhet, and Jean-Louis Guéant, "Serum concentrations of sex hormone binding globulin are elevated in kwashiorkor and anorexia nervosa but not in marasmus", American Journal of Clinical Nutrition, 2002; 76, 239-244.

[31] Reeds P. J and Laditan, A. A, "Serum albumin and transferrin in protein-energy malnutrition, their use in the assessment of marginal undernutrition and the prognosis of severe undernutrition", British Journal of Nutrition, 1976; 36 (2): 255-63.

[32] Malcolm G. Coulthard, "Oedema in kwashiorkor is caused by hypoalbuminaemia" Paediatrics International Child Health, 2015; 35 (2): 83-89. doi:10.1179/2046905514Y.0000000154.
[33] Olaf M. \& Michael K, "Malnutrition and health in developing countries", Canadian Medical Association Journal, 2005; 173, 3 doi: $10.1503 /$ cmaj. 050342 .

[34] Taiwo, O. O \& Thomas, KD, "Plasma biochemical parameters in Nigerian children with protein energy malnutrition" East African Medical Journal, 1992; 69 (8): 428-32.

[35] Mohammad Ali Kalantar Motamedi, Maryam Barzin, a Mohammadreza Ebrahimi, Reza Ebrahimi, and Alireza Khalaj, "Severe fatal protein malnutrition and liver failure in a morbidly obese patient after mini-gastric bypass surgery: Case report", International Journal of Surgical Case Reports, 2017; 33: 71-74. doi: 10.1016/j.ijscr.2017.02.033.

[36] Black R. "Micronutrient deficiency an underlying cause for morbidity and mortality" Bulletin of World Health Organization 2003; 81: 79

[37] Pujitha Wickramasinghe, "Micronutrients in childhood nutrition", Sri Lanka Journal of Child Health, 2013; 42 (4): 157-165.

[38] Diaz JR, de las Cagigas A, Rodriguez R, "Micronutrient deficiencies in developing and affluent countries [review]", European Journal of Clinical Nutrition, 2003; 57: S70-2.

[39] Donnen P, Brasseur D, Dramaix M, Vertongen F, Zihindula M, Muhamiriza M, Hennart, P, "Vitamin A supplementation but not deworming improves growth of malnourished preschool children in eastern Zaire", Journal of Nutrition, 1998; 128: $1320-1327$.

[40] Vinicius J. B. Martins, Telma M. M. Toledo Florêncio, Luciane P. Grillo, Maria do Carmo P., Franco, Paula A. Martins, Ana Paula G. Clemente, Carla D. L. Santos, Maria de Fatima A., Vieira, and Ana Lydia Sawaya, "Long-Lasting Effects of Undernutrition", International Journal of Environmental Research, 2011; 8 (6): 1817-1846.

[41] Koletzko, B., Abiodun, P. O., Laryea, M. D., Bremer, H. J, "Fatty acid composition of plasma lipids in Nigerian children with protein-energy malnutrition", European Journal of Pediatrics, 1986; 154: 109-115. 